University of South Florida

DIGITAL COMMONS

Digital Commons @ University of

@ UNIVERSITY OF SOUTH FLORIDA

South Florida

Educational Leadership and Policy Studies Faculty Publications

$9-2010$

\title{
A Study of Group Dynamics in Educational Leadership Cohort and Non-Cohort Groups
}

Zorka Karanxha

University of South Florida, karanxha@usf.edu

Bobbie J. Greenlee

Follow this and additional works at: https://digitalcommons.usf.edu/els_facpub

Part of the Education Law Commons, and the Elementary and Middle and Secondary Education Administration Commons

\section{Scholar Commons Citation}

Karanxha, Zorka and Greenlee, Bobbie J., "A Study of Group Dynamics in Educational Leadership Cohort and Non-Cohort Groups" (2010). Educational Leadership and Policy Studies Faculty Publications. 38.

https://digitalcommons.usf.edu/els_facpub/38

This Article is brought to you for free and open access by Digital Commons @ University of South Florida. It has been accepted for inclusion in Educational Leadership and Policy Studies Faculty Publications by an authorized administrator of Digital Commons @ University of South Florida. For more information, please contact digitalcommons@usf.edu. 


\title{
A Study of Group Dynamics in Educational Leadership Cohort and Non-Cohort Groups
}

\author{
Bobbie J. Greenlee \\ Zorka Karanxha \\ University of South Florida
}

\begin{abstract}
The purpose of this study was to examine group dynamics of educational leadership students in cohorts and make comparisons with the group dynamics characteristics of non-cohort students. Cohorts have emerged as dynamic and adaptive entities with attendant group dynamic processes that shape collective learning and action. Cohort $(n=42)$ and non-cohort $(n=51)$ students were surveyed on group variables of participation, communication, influence, trust, cohesiveness, empowerment, collaboration, and satisfaction. Descriptive statistics and effect size analyses were used for data analysis. Significant differences were identified in trust, cohesiveness, and satisfaction. However, findings show little effect on cohort structures in the areas of participation, communication, influence, empowerment, and collaboration.
\end{abstract}

Leadership preparation programs have been under scrutiny from policymakers, practitioners and from within the leadership professorate for more than two decades (Levine, 2005; Nation Commission on Excellence in Educational Administration, 1987). Criticism has revolved on all aspects of the leadership preparation including recruitment, curriculum, and delivery of curriculum. The field's response to critique and calls for reform resulted in innovative and authentic approaches to both curriculum and its delivery (Murphy, 1993; Young \& Brewer, 2008). Much of the literature on educational leadership preparation reform focuses on delivery models. Delivery innovations include weekend courses, summer institutes, and online course offerings (Jackson \& Kelley, 2002). The cohort model emerged in the early 90 s as one of the most prevalent models. In 1995, a study of UCEA member institutions reported 50\% were using cohorts at the master's level (Norton, 1995). Five years later, in a broader investigation of educational leadership master's programs 63\% were using cohorts (Barnett, Basom, Yerkes, \& Norris, 2000).

The establishment of cohorts in educational leadership programs has gained substantial popularity and is consistent with research findings on benefits of preparation of students in cohorts (Barnett et al., 2000; Durden, 2006). Cohorts have emerged as dynamic and adaptive entities that develop as members interact over time. 


\section{Greenlee \& Karanxha / COHORT GROUP DYNAMICS}

These group interactions shape collective learning and action in cohorts. However, there may be both opportunities and risks for students within cohort structures. Our purpose here is to identify group dynamics that have research-based relationships to group effectiveness and therefore should be the focus for interventions to enhance cohort functioning.

\section{Cohorts}

Generally, a cohort consists of a group of students who enter and move through a program of studies together (Barnett \& Muse, 1993). A cohort group is acknowledged as being a distinct, interdependent group, markedly different from non-cohort groups who as separate learners proceed course by course with random groupings of other students. Cohort structures are a collegial support system to improve the teaching and learning process (Barnett \& Muse, 1993).

Cohort structures vary depending on program design and goals, and they follow three basic models: closed, open, and fluid (Barnett \& Muse, 1993; Teitel, 1997). In a closed cohort, a selected group of students takes all of their courses together in a prearranged sequence. The open cohort essentially remains intact for core courses, but students take limited coursework on an individual basis to fulfill personal needs or university requirements. The fluid cohort is more flexible, allowing students to enter at different times and select courses based on their own needs.

Individuals have reported that the cohort experience advanced a sense of community, increased their social capital, and promoted professional collaboration (Hill, 1995; Tareilo, 2007; Whitaker, King, \& Vogel, 2004). Positive academic outcomes of cohort structure include enhanced learning, reflective abilities, and multiple perspectives for problem solving (Barnett et al., 2000; Hill, 1995; Norton, 1995). In addition, research shows an increase in motivation, commitment and persistence among cohort students (Hill, 1995). Program benefits include clearer course sequencing, increased associations between faculty and students, development of professional networks, and higher degree completion rates (Barnett \& Muse, 1993; Barnett et al., 2000; Hill, 1995; Scribner \& Donaldson, 2001).

Proponents of cohorts argue that the model is more than a group of students with a common schedule, but rather an adult learning model characterized by affiliation and strong sense of purpose (Barnett \& Muse, 1993; Basom, Yerkes, Norris \& Barnett, 1996; Donaldson \& Scribner, 2003). The cohort model is successful when faculties are effective in developing a learning community characterized by trust, openness, and empowerment (i.e. empowering students as adult learners) (Brown-Ferrigno \& Muth, 2001; Hill, 1995; Merriam \& Cafferella, 1999). There is also evidence that the cohort structure contributes to practicing collaborative problem solving, sharing authority for learning, and building teamwork skills that are increasingly expected among school faculties (Barnett et al., 2000; Brown-Ferrigno \& Muth, 2001). Cohort students who interact with each other to 
work collaboratively for the betterment of all are better able to transfer this interactive and collaborative approach to their schools (Hill \& Ragland, 1995). Durden's (2006) study on the cohort effect of a group of educational leadership students showed that students valued the richness of their learning experiences and the advantage of working together to complete a degree. Durden concluded that the cohort experience was able to "evoke an image of the type of collegiality that will serve as a model for these aspiring leaders in their future roles" (p. 124). Supportive relationships created and maintained in cohorts have substantial benefits for students in these programs and, many times, continue beyond completion of the program (Barnett el al., 2000; Hill, 1995; Scribner \& Donaldson, 2001). Findings also suggest that participation in cohort groups cultivated the aspiring school leaders' skills for building collaborative school cultures as much as the curriculum.

In an effort to capture characteristics of promising school administrator preparation programs, Leithwood, Jantzi, and Coffin (1995) studied the consequences of the Danforth Foundation Program for the Preparation of School Principals. Not only did the graduates of the program value the cohort experience, but teachers working for principals who were trained in cohorts rated them highly on effective leadership qualities. Leithwood and colleagues reported that features of the formal preparation programs-cohort groups, internships, mentor relations, and problem-based learning activities-foster real life problem-solving skills of participants and were valuable strategies for developing effective school leadership.

Even though the benefits of a cohort structure are numerous, disadvantages for both faculty and students are also reported. Researchers have reported domineering students, inappropriate forms of interaction, and tension between faculty and students (Barnett et al., 2000; Scribner \& Donaldson, 2001; Teitel, 1997). Furthermore, individual talents of students might get lost in the group, and the peer pressure among students to fit in is higher (Hill, 1995). Also, problems of clique development result in a sense of isolation for some individuals (Sapon-Shevin \& ChandlerOlcott, 2001). Other problems include inflexible program structure and personal costs to both faculty and students (Barnett et al., 2000).

Increasingly, cohorts are becoming the preferred organizational structure in educational leadership programs. Supportive relationships created and maintained in cohorts have substantial benefits for students in these programs and, many times, continue beyond completion of the program (Barnett el al., 2000; Hill, 1995; Scribner \& Donaldson, 2001). The functionality and productivity of cohorts are the consequence of group processes or group dynamics. A comprehensive study of group processes or group behavior is essential to understanding the contributions of cohorts to students' persistence and academic performance in educational leadership programs. Previously, the literature exploring cohorts has examined structural 
arrangements of cohorts and the impact of cohorts on students. Ultimately, however, educational leadership faculty must be concerned with group dynamics that are most likely to hinder or contribute to the overall positive effects of the cohort experience.

\section{Group Dynamics}

Group dynamics, as a conceptual framework, provide a heuristic approach for understanding how effective groups both work and advance our knowledge of the impact of those processes on students in cohorts. The characteristics of effective groups include clear purpose; shared leadership; open communication; and high levels of inclusion, acceptance, support, and trust (Johnson \& Johnson, 2003; Larson \& LaFasto, 1989; Zander, 1982). Group dynamics can be conceptualized as falling into the following interrelated categories: participation, communication, collaboration, influence, trust, cohesion, empowerment, and satisfaction.

A fundamental characteristic of effective groups is that members will participate in group discussions and consider contrasting opinions and ideas. Generally, allowing for diverse ideas and perspectives leads to improved performance. In order for the group to realize high levels of participation, each member should be encouraged to contribute his or her views. Participation by all members is crucial to effective group performance (Fisher \& Ellis, 1990).

Frequency and quality of group communication is related to enhanced group decision-making and cohesiveness (Hirokawa, 1988; Shaw, 1981). Based on a review of the literature on group dynamics, Shaw (1981) found that highly cohesive groups communicate more and have more positive exchanges. Groups that interact in an environment of mutual respect and trust engage in more supportive communication (Fisher \& Ellis, 1990). Supportive communication is authentic, open, truthful, and compassionate. Furthermore, members of highly cohesive groups are more inclined to take risks in the form of expressing opinions, receiving and giving both positive and negative feedback, and debating ideas (Fisher \& Ellis, 1990; Stokes, 1983).

Educators that work collaboratively grow both personally and professionally as they become more analytical and more willing to apply new ideas (Porter, 1987). Meaningful dialogue among group members is central to establishing trust and effective collaboration (Senge, Kleiner, Roberts, Ross, \& Smith, 1994). True collaboration, with a focus on common goals and a sincere desire to benefit all members, promotes trust among group members.

Individuals who identify with a group are more likely to be influenced by the preferences and behaviors that typify the group (Terry \& Hogg, 1996). The group influences how members set their goals, how much effort will be exerted to achieve those goals, and how they will persist in the face of difficulty (Bandura, 1997). Views of individual group members are clearly influenced by majority opinions of the group; however, those with minority opinions can influence the majority. Minority 


\section{Greenlee \& Karanxha / COHORT GROUP DYNAMICS}

opinions may influence the group if their arguments are well-reasoned, confident, and flexible (Forsyth, 1999). When group members feel they are working on important issues that they can influence, they feel more strongly connected to the group or more cohesive.

Trust is a crucial quality for cohesiveness and is the starting point for group problem solving (Malnight, 1989). Some scholars have argued that trust advances greater use of honest, unambiguous communication in groups (Deutsch, 1973; Zand, 1972). However, both trust and candid communication take time and a shared sense of purpose (Fisher \& Ellis, 1990). Fisher and Ellis explained that interpersonal trust and self-disclosure take time, history, conversation, and a belief in other's capabilities. McClure (2005) concurred that trust and self-disclosure are not only determinants of cohesion, they are also measurable attributes of cohesive groups.

Cohesiveness is probably the most essential construct of group behavior (Zander, 1982). Importantly, group cohesion is linked to improved performance (Evans \& Dion, 1991) and effective communication (Rosenfeld \& Gilbert, 1989). Even with the considerable amount of research on group cohesion, there is no single agreed upon definition of cohesion. Early literature defined group cohesion as the sum of all the forces which act on individuals to remain in the group (Festinger, Schachter, \& Back, 1950). Critics of this model claimed that what actually kept groups together was their resistance to disruptive forces (Gross \&
Martin, 1952). Still the work of other scholars suggests that several factors contribute to group cohesiveness, such as risk taking, commitment to the group's purpose, interpersonal attraction, and quality of group interaction (Carron, 1982; Owen, 1985; Stokes, 1983). Some research on groups report that all groups naturally evolve toward cohesiveness (Alexander, 1985). Even though researchers cannot agree on all the dimensions that describe cohesiveness, group cohesion influences members' behaviors in important ways: high levels of group cohesion have been associated with greater commitment to group goals, participation, communication, and self-confidence (Toseland \& Rivas, 2001).

Group cohesiveness is enhanced when members are empowered to meaningfully impact group work processes. Group empowerment is a shared belief that the group can be effective (Shea \& Guzzo, 1987). Empowered groups share responsibility, motivation, and influence group process and effectiveness (Mathieu, Gilson \& Ruddy, 2006). Individuals are empowered when they have input into the direction of the group and when they are actively involved in the work of the group (Toseland \& Rivas, 2001).

Collective efforts to accomplish group goals help maintain group cohesion and increase group satisfaction. Group satisfaction can be defined as a sense of fulfillment about how well group members work together (Hecht, 1978). Satisfaction will be high when group members feel included and when they have participated. Similar to group communication, members feel 
more satisfied in group participation when they believe that their opinions are valued (Anderson \& Martin, 1995).

\section{Cohorts as Groups}

With more educational organizations embracing cohorts as basic building blocks of their programs, cohorts, with structured interactive experiences, advance a group sense of affiliation, motivation, and coordination of efforts (Young \& Brewer, 2008). Group development in cohorts is characterized by "interaction (which results in cohesiveness among group members), purpose (which promotes collaboration), and interdependence (which represents the hallmark of a group's realness)" (Norris \& Barnett, 1994, p. 32). Through group experiences, students in cohorts develop increased empowerment, collegiality, affiliation, support, community, and trust (Barnett et al., 2000).

The functionality and productivity of cohorts are the consequence of group processes or group dynamics. A comprehensive study of group dynamics is essential to understanding the contributions of cohorts to students' persistence and academic performance in educational leadership programs. Previously, the literature exploring cohorts has examined structural arrangements of cohorts and the impact of cohorts on students. Ultimately, however, educational leadership faculty must be concerned with the group dynamics that are most likely to hinder or contribute to the overall positive effects of the cohort experience. Moreover, research findings report generally positive effects of cohort arrangements, but rarely make direct comparisons to non-cohort groups. The purpose of this study is to examine whether there are any differences on characteristics of group dynamics such as participation, communication, collaboration, influence, trust, cohesion, empowerment, and satisfaction between cohort and non-cohort students in an educational leadership preparation program.

\section{Method}

\section{Sample}

Purposeful sampling was used to gain insight and understanding from a sample that could be particularly informative (Creswell, 2008). The participants in the study were students enrolled in master's degree courses in the educational leadership preparation program offered at a large metropolitan state university located in the southeastern United States. At the time of the study, the educational leadership department incorporated both a closed cohort groups of students who took all of their courses together in a prearranged sequence and a non-cohort groups with students who enrolled in courses and completed the program on an individual basis. The program was the same for both cohort and non-cohort students.

The sample consisted of educational leadership students enrolled in one of five courses identified as cohort-only or open enrollment. From these five courses, two had only graduate students admitted to one of two cohorts $(n=63)$ and three were open 
to graduate students who were not members of any cohort $(\mathrm{n}=85)$. One cohort $(\mathrm{n}=28)$ was in their final semester and enrolled in the administrative practicum, while the other cohort students $(n=35)$ were enrolled in courses and had completed half of the 36 semester hour program. Of the noncohort students, 27 were in their final semester and enrolled in the administrative practicum. The remaining non-cohort students had the option of enrolling in a selected number of courses offered. Since course-taking patterns were not managed in the program for non-cohort students, these students were at various points in the completion of their degree.

Every student enrolled in any of the five courses sampled received an invitation to participate in the study via email or announcement on Blackboard. Each student had access to the online survey and could complete it only once. A total of 93 students, representing $62.8 \%$ response rate, participated in the study. Forty-two participants were members of a cohort $(66.7 \%$ response rate) and 51 were non-cohort students who moved through the program at their own pace (60\% response rate). Participation in the study was voluntary and students' anonymity was protected. Demographic information on participants was not gathered from the students.

\section{Instrument}

We used survey research methodology to conduct this study. A survey instrument developed by Schultz, Israel, and Lantz (2003) designed to measure participation, communication, influence, trust, cohesion, group empowerment, and collaborative work of effective groups was adapted and used for this study. This instrument was selected because of its comprehensiveness in measuring several concepts of group dynamics. Their instrument for evaluating dimensions of group dynamics was developed to assess key dimensions of group characteristics of service providing, community based, public health partnerships. Schultz and colleagues describe the instrument as a group-dynamics questionnaire for "collaborative efforts whose success relies in part on the development of effective and equitable working relationships among members" (p. 258). The construction of their instrument draws heavily on the work of scholars (Alexander, 1985; Burns \& Gragg, 1981; Johnson \& Johnson, 2003; Seashore, Lawler, Mirvis, \& Cammann, 1983) who conceptualized and categorized the characteristics of effective groups. The conceptual models for effective groups that the instrument is based on can be applied to cohorts.

For the purposes of this study, the Schultz, Israel, and Lantz questionnaire was modified by removing sections that were less applicable to student groups. Deleted sections included "meeting organization, agenda setting, facilitation, and staffing;" "decisionmaking procedures;" and "addresses conflicts and problems." The revised questionnaire used in this study had eight subscales: participation, communication, collaboration, influence, trust, cohesiveness, 
empowerment, and satisfaction. Modifications to the original items were made to change the questions into statements. For example, "How often do you suggest new ideas?" was changed to the statement "I suggest new ideas" and scored with a five point Likert-type scale indicating the frequency of the particular behavior as never, seldom, sometimes, usually, or always. Also, wordings on the items were changed to reflect an educational environment instead of a public health context. For instance, "group meetings" was changed to "class meetings." The items for both cohort and non-cohort groups with the exception of items related to cohesion, group empowerment, and benefits of participation were worded the same. For example, in items that stated: "I feel like I belong to the cohort;" "the cohort influences the instructor to modify assignments;" and "participating in this cohort has made the program more enjoyable," wording was changed so that "cohort" was replaced with "class" or "class members." The revised items were assembled into an online survey. Students enrolled in the five identified courses sampled for this study were contacted via e-mail and were asked to complete the online survey.

After the removal of irrelevant items, the survey instrument measured eight constructs of effective groups with 52 items. For our sample, scales for all but one of the constructs had high Cronbach alphas (see Table 1). The survey used in this study had a Cronbach alpha of 0.84 for this sample, which falls within the acceptable range thus establishing the reliability of the instrument. 


\section{Greenlee \& Karanxha / COHORT GROUP DYNAMICS}

Table 1:

Group constructs and indicators incorporated in questionnaire

\begin{tabular}{|c|c|c|c|}
\hline Construct & Indicators & $\begin{array}{l}\text { Number } \\
\text { of } \\
\text { Items }\end{array}$ & $\begin{array}{l}\text { Cronbach } \\
\text { Alpha }\end{array}$ \\
\hline Participation & $\begin{array}{l}\text { Suggest ideas, add information and contribute to } \\
\text { discussion } \\
\text { Good listener } \\
\text { Support ideas of others and group works together } \\
\text { Friendliness of group members }\end{array}$ & 13 & 0.755 \\
\hline Communication & $\begin{array}{l}\text { Willing to speak and express opinions } \\
\text { Members feel comfortable expressing points of view } \\
\text { Am listened to and listen to others }\end{array}$ & 7 & 0.730 \\
\hline Collaboration & $\begin{array}{l}\text { Members work together and solve problems } \\
\text { Each member contributes and has a voice } \\
\text { Satisfied with and committed to decisions made by class } \\
\text { members }\end{array}$ & 8 & 0.798 \\
\hline Influence & $\begin{array}{l}\text { Certain members talk more and opinions are weighted } \\
\text { more } \\
\text { Certain members have more influence over topics } \\
\text { discussed and over the decision-making process } \\
\text { Opinions of others are listened to } \\
\text { Pressured to go along with decisions of cohort }\end{array}$ & 9 & 0.770 \\
\hline Trust & $\begin{array}{l}\text { Trust and openness exists among class members } \\
\text { Trust and openness has increased and continues }\end{array}$ & 3 & 0.748 \\
\hline Cohesiveness & $\begin{array}{l}\text { Feelings of belonging } \\
\text { Sense of ownership over what cohort does } \\
\text { Desire to remain in group }\end{array}$ & 3 & 0.823 \\
\hline Empowerment & $\begin{array}{l}\text { Influence on group goals and decisions } \\
\text { Attainment of group goals } \\
\text { Influence on instructor, content, and program }\end{array}$ & 7 & 0.741 \\
\hline Satisfaction & Satisfied with personal growth and with program & 2 & 0.974 \\
\hline
\end{tabular}




\section{Greenlee \& Karanxha / COHORT GROUP DYNAMICS}

\section{Statistical Analysis}

We conducted two tailed t-test analyses for independent groups to determine whether or not there were any differences in group dynamics characteristics between the cohort and non-cohort students. In addition, we calculated effect sizes for cohort and non-cohort groups. The effect-size statistic measured the size or magnitude of relation between two variables. Effect sizes complemented null hypothesis significance testing by illuminating the practical significance of the research findings (Hogarty \& Kromrey, 2001). We used Cohen's (1988) method of determining effect sizes, which involved calculating the mean perception of the cohort group minus the mean perception of the non-cohort group divided by the pooled standard deviation of that difference score. A positive effect size indicated that the cohort group was perceived to be less variable than the non-cohort group; a negative effect size indicated that the non-cohort group was perceived to be less variable than the cohort group, and an effect size of zero indicated perceptions of equivalent cohort and non-cohort variability. Cohen (1988) provides a framework for labeling effect sizes as small (0.20), medium (0.50), and large (0.80) but cautions about using such a framework out of context. Table 2 represents all corrected sizes due to concerns for the over estimation of population effect sizes (Hedges \& Olkin, 1985).

Confidence intervals for the effect size are the range of scores on the dependent variable that should contain the true difference between means for the population. The practical significance of findings is enhanced because confidence intervals for effect size highlight the lower and upper bounds of what the true value of a parameter might be. When the confidence interval does not include zero, there can be reasonable confidence that the result is useful for decision making (Rosenthal, 2000). The confidence intervals and effect size statistics are shown in Figure 1.

\section{Limitations}

A possible limitation of this study is the use of self reports in the survey. This introduces the potential for response bias, as participants may exaggerate or inaccurately report their performance. In the absence of direct investigation of group behaviors of cohort and non-cohort students, only limited speculations should be made. A second limitation of the study concerns generalizability of findings due to the purposeful sampling utilized for this research. We sampled only students in one program and, henceforth, do not claim that we can generalize the findings for programs across the nation. A third limitation of the study pertains to what stage of program completion were the students who participated in the study. Almost half of the sample (cohort=28 and non-cohort=27) was in the final class of the program, the rest of the cohort sample was halfway through the program, while the rest of noncohort students could have been at any stage in their studies. 


\section{Greenlee \& Karanxha / COHORT GROUP DYNAMICS}

\section{Findings}

Following the recommendations of the American Psychological Association on reporting effect sizes as the primary outcome of a research study (APA, 2001) rather than just statistical significance, we will concentrate on reporting and explaining the effect sizes and confidence intervals for effect size of our findings. Such a discussion will assist the field in determining whether: "First, the findings are real rather than attributed to chance .... Second, if the effect is real, how large is it? Third, is the effect large enough to be useful ... (Vaske, Gliner, \& Morgan, 2002, p. 288). Specifically, we used effect size to determine the practical significance of the noteworthiness of the findings (APA, 2001).

As Table 2 (see Appendix A) demonstrates, the two-tailed t-test analysis showed that there were significant statistical differences between the two groups (cohort and non-cohort) on three group dynamic characteristics: trust, cohesiveness, and satisfaction at $a<0.00$. The cohort students rated these three measures higher than the non-cohort students. There were no significant statistical differences in participation, communication, collaboration, influence, and empowerment. The cohort students had higher means on all these measures, with the exception of participation, however none of these characteristics reached statistical significance (see Table 2 in Appendix A). Empowerment had the lowest mean at 3.52 for cohort students and 3.26 for non-cohort students. Influence was the second lowest mean for both groups (cohort students 3.62 and non-cohort students 3.54). Satisfaction had the highest mean for cohort students at 4.78 compared to 2.98 for the non-cohort students. Cohesiveness had the second highest mean for cohort students at 4.41 and non-cohort students at 3.82 .

\section{Participation}

Students' perceived level of participation was assessed with items that asked the extent to which they suggested new ideas, provided information, expressed their opinion, related personal experiences to course topics, and contributed new or additional items for discussion. Participants were also asked to rate the extent to which they perceived they were good listeners, supported of other's ideas, pointed out ways to proceed when the group was stuck, and invited others to work on specific issues. Comparisons of measures derived from cohort and non-cohort groups evidenced a small negative effect $(d=-0.10 ; 95 \%$ confidence interval $(\mathrm{CI})$ of -0.51 to 0.31 ) indicating a difference favoring the non-cohort group. Furthermore, this finding suggests that $54 \%$ of non-cohort students rated their participation levels higher than the average person in the cohort group.

\section{Communication}

Cohort and non-cohort members comfort levels for expressing opinions was assessed using items that asked the extent to which they and others in the class were comfortable expressing their point of view, their own and the opinions of others were listened to, and 
whether their willingness to speak out in class has persisted. Analysis of this scale produced the smallest effect size statistic ( $\mathrm{d}=0.06$; $95 \% \mathrm{CI}$ of -0.35 to 0.47 ) which suggests that there is little difference between cohort and noncohort students perceived levels of communication with $50 \%$ of the cohort participants rating their communication higher than non-cohort students.

\section{Collaboration}

The extent to which the groups work together was measured using items that asked how well class members worked together, contributed to class work, solved problems together, were committed to decisions made by the group, and were satisfied with members' capacities to work together. Statistical analysis revealed a positive effect $(\mathrm{d}=0.28 ; 95 \% \mathrm{CI}$ of -0.13 to 0.69$)$ for the cohort group. Even though this would generally be considered a small effect, the rating on collaboration of the average person in the cohort group exceeded the ratings of $62 \%$ of the noncohort group.

\section{Influence}

Items measuring influence asked participants to what extent they felt pressured to go along with decisions of the cohort even if they may not have agreed. Items measured whether certain group members talked more than others at class meetings; had more influence over topics discussed; had more influence over decision making; or dominated class meetings. Since the items in this scale are negatively worded, they were reverse scored in order to match the scale of the other items. Analysis produced a small positive effect $(\mathrm{d}=0.09 ; 95 \% \mathrm{CI}$ of- 0.32 to $0.50)$ for the cohort group which suggests that approximately $52 \%$ of the cohort students rated this construct higher than non-cohort students.

\section{Trust}

To assess students perceived level of trust in cohort and non-cohort groups, students were asked to respond to items that asked the extent to which trust and openness existed between class members, whether trust had increased since beginning the program, and whether trust was expected to increase through the remainder of the program. Analysis of the average perception of cohort and non-cohort groups on trust produced a moderate positive effect $(\mathrm{d}=0.71,95 \%$ CI of 0.28 to 1.13) which reveals significant statistical differences. This effect size statistic indicates that the average person in the cohort would rate trust higher than $76 \%$ of the non-cohort group.

\section{Cohesiveness}

Items that assessed cohesion asked participants the extent to which they felt they belonged to a group, had a sense of ownership over what the group did, and whether they wanted to maintain their affiliation with the group. This measure presented a moderate positive effect $(\mathrm{d}=0.60 ; 95 \% \mathrm{CI}$ of 0.18 to 1.02). This means that the rating for cohesiveness of the average person in the cohort exceeds the ratings of $73 \%$ of the non-cohort group. 


\section{Greenlee \& Karanxha / COHORT GROUP DYNAMICS}

\section{Empowerment}

This scale measured group member perceptions of empowerment based on the dimensions of determination and impact. Items assessed the extent to which group members influenced decisions, influenced the instructor, and were effective in achieving goals.. The results of analysis showed a positive effect $(\mathrm{d}=$ 0.29 ; $95 \%$ CI of -0.12 to 0.70 ). Such an effect suggests that almost $60 \%$ of the cohort students rated this construct higher than the non-cohort students.

\section{Satisfaction}

Items assessed students' perceptions of their preference for going through the educational leadership program together in a cohort. Cohort students were asked if participating in the cohort had made the program more enjoyable and had provided personal growth $(\mathrm{m}=4.78)$. They indicated a strong preference for the cohort arrangement, with $81 \%$ of the group reporting "definitely." On the other hand, non-cohort students were asked if they would have preferred to go through this program as part of a cohort and if participating in a cohort would have made the program more enjoyable $(m=2.98)$. As for each group dynamics component, cohort and non-cohort member perceptions were assessed as an aggregate. Notably, the non-cohort students did not have clear consensus on whether they would have been more satisfied in a cohort structure. When asked if they would have preferred to go through the program as part of a cohort and if that would have made the program more enjoyable, $43 \%$ of the non-cohort group indicated probably or definitely, while about 50\% indicated only possibly or not at all. Comparison of group means resulted in significant differences and yielded a large effect size ( $d=1.42 ; 95 \%$ CI of 0.96 to 1.87). The large effect size statistic suggests that the average rating for the cohort group exceeds the ratings of $92 \%$ of non-cohort group.

Analysis of differences (see Table 2 and Figure 1 in Appendices) in cohort and non-cohort groups' relationship on the group dynamics components of trust, cohesiveness, and satisfaction produced statistically significant results. Trust yielded an effect size of 0.71 with a confidence interval for the effect size ranging from 0.28 to 1.13 . The effect size for the groups' sense of cohesiveness was 0.60 with a confidence interval ranging from 0.21 to 1.02 . On a measure of the satisfaction with the cohort structure, analysis of each group's perceived satisfaction and preference for participation in a cohort arrangement yielded a large effect size of 1.42 with a confidence interval ranging from 0.96 to 1.87. The other group dynamics characteristics, namely, participation, communication, collaboration, influence, and empowerment, yielded relatively small effect size statistics ranging from 0.06 to 0.29 with the exception of participation which is negatively associated with cohort membership, yielding a small effect size of -0.10 with a confidence interval ranging from -0.51 to 0.31 . For empowerment, the effect size was 0.29 with a confidence interval ranging from -0.12 to 0.70 . Collaboration had a 0.28 effect size with a confidence interval 


\section{Greenlee \& Karanxha / COHORT GROUP DYNAMICS}

ranging from -0.13 to 0.69 . Communication produced an effect size of 0.06 with a confidence interval ranging from -0.35 to 0.47 . The effect size for influence was 0.09 with a confidence interval ranging from -0.32 to 0.50 .

\section{Discussion}

Our research confirms the findings of previous studies (Barnett \& Muse, 1993; Basom et al., 1996; BrownFerrigno \& Muth, 2001; Donaldson \& Scribner, 2003; Hill, 1995; Young \& Brewer, 2008) on cohorts in educational leadership programs that suggest a strong sense of affiliation and a sense of purpose among cohort students. The cohort participants in our study felt a very strong sense of trust and cohesiveness due to the cohort structure of the program. The climate of trust essential for cooperative behavior and successful group processes identified in previous investigations (Burnaford \& Hobson, 1995; Teitel, 1997) is positively associated with a cohort arrangement.

What is distinctive in this study is its examination of group dynamics of both cohort and non-cohort groups. The findings indicate that open communication, working collaboratively, group influence, and empowerment seem to be positively, albeit weakly, associated with cohort structures. Of particular interest is the finding that group members' participation in discussions was higher for non-cohort students than for cohort students. This was contrary to what we expected with the findings of higher levels of trust and cohesiveness within the cohort group. One explanation may be the problem of groupthink. The symptoms of groupthink include: conformity, censorship of deviations from group consensus, shared illusion of agreement, and screening of adverse information (Janis, 1982). Cohorts, as highly cohesive groups, may produce a conformity that leads to groupthink. Although cohesiveness is desirable for the cohort effects of completion rate, motivation, sense of community, and collaboration, it also produces groupthink behaviors: limited discussion, alternatives not considered, and selective bias, which leads to defective decision making (Janis \& Mann, 1977). This finding is consistent with previous research which found that the intense togetherness of the cohorts created problems related to groupthink (Barnett et al, 2000; Scribner \& Donaldson, 2001).

Communication, in particular, is essential for a collection of individuals to become a cohesive group that can influence collective action (Drury \& Reicher, 1999). Yet, in the present study, the difference between the cohort and non-cohort group in communication was negligible. On the other hand, the construct of communication provided the highest mean in the non-cohort group of all the other group dynamics characteristics. It appears that being enrolled in graduate classes seems to facilitate communication itself. The cohort structure does not seem to make a difference in such an important characteristic of group dynamics. This finding does not support previous research which suggests superiority of the cohort structure when it comes to 


\section{Greenlee \& Karanxha / COHORT GROUP DYNAMICS}

communication (Alexander, 1985; Barnett et al., 2000; Young \& Brewer, 2008). These results provide evidence that communication may not be as dependent on cohesiveness and trust as has been reported.

Group members are empowered to accomplish their goals when they share common vision and expectations (Bandura, 1997). Cohort groups experience empowerment as adult learners and become much more likely to influence curricular content and activities (Barnett et al., 2000; Maher, 2005). Evidence in this study shows very little difference in empowerment between cohort and non-cohort groups. Moreover, the empowerment characteristic had the lowest mean for the cohort group of all the other group dynamics characteristics. These findings raise questions about the usefulness of assessing empowerment as an indicator of effective groups.

If influence varies with the level of group cohesiveness (McGrath, 1984), it would be logical to expect influence in cohort groups to be significantly higher than for non-cohort groups. The low mean for group influence for the cohort raises some interesting issues about the role of influence in cohorts and the relationship of group influence with cohesiveness. Perhaps more importantly, the findings may have implications for development of leadership capacity. Effective educational leaders stimulate, develop, and elevate their people to higher levels of potential through a process of mutual influence (Bass \& Avolio, 1994). Evidence from the research suggests that group influence, like communication, may not be associated with trust or group cohesiveness. Data from this study suggest that collaboration, influence, and empowerment do not distinguish cohorts from non-cohort groups.

Of the eight group dynamics characteristics measured, trust, cohesiveness, and satisfaction in the cohort group differed significantly with the non-cohort group. Evidence from this research supports the findings in the literature and suggests that being in a cohort is associated with high levels of trust and a sense of cohesiveness that the non-cohort students did not show. Studies of student cohorts in higher education indicate that being part of a cohort contributes to the development of mutual trust (Teitel, 1997) and enables students to learn "in a climate of cooperation and trust" (Burnaford \& Hobson, 1995, p. 69). Such a finding has practical implications for leadership programs, especially if they are trying to increase the sense of trust that leads to the development of a sense of purpose among students. Scholars report "a direct relationship between the nature and consistency of interaction and support that is available and the level of trust achieved" (Thanos, 1990, p. 33). Trust takes time to develop and the cohort structure appears to provide a better environment for it to build up.

Cohort structures seem to
facilitate members' sense of
cohesiveness increasing their desire to
stay with the group and remain united
in pursuit of group goals. The process of
working together and the quality of
group interactions are factors that
produce a sense of belonging or




\section{Greenlee \& Karanxha / COHORT GROUP DYNAMICS}

cohesion (Turner, Hogg, Turner, \& Smith, 1984; Zaccaro \& McCoy, 1988). Members of cohesive groups communicate frequently and for longer periods and they also display greater openness with each other (Kirmeyer \& Lin, 1987; Shaw, 1981). The findings of this study suggest that being in a cohort provides a sense of cohesiveness and ownership in group activities and that the distinction between the two groups of students is easily obvious.

Similarly, group cohesion is a key determinant for both group productivity and member satisfaction (Cohen \& Bailey, 1997; Mullen \& Copper, 1994). Members of a cohesive group (a) are attracted to the group and its members, (b) are interdependent in pursuit of common goals, and (c) have high levels of satisfaction from the association with the group (Hogg, 1993). Given the significance of group cohesion, it is not surprising that cohort students experience increased motivation and commitment to persist in their program of study together (Barnett et al., 2000; Hill, 1995; Norton, 1995). Students who were part of cohorts were highly satisfied. They enjoyed the experience greatly and reported to have experienced personal growth. While the non-cohort students appeared to prefer the non-cohort program, many have felt that a cohort experience would have been beneficial.

It would appear, then, that many of these characteristics that lead to effective group processes are present in both cohort and non-cohort groups. The non-cohort group might vary in the degree to which the members identify themselves as a group. Even though group membership of the non-cohort students fluctuated as opposed to permanent membership in the cohort group, non-cohort members formed subgroups that worked together and moved themselves through courses as a team. It is possible that these subgroups of students may have had high group identity and strong relationships just as the traditional cohorts. It may be that the defining group characteristics which differentiate a cohort are just as strong within stable subgroups found in noncohort arrangements.

Additionally, we need to take into consideration that the faculty and their teaching might in many ways have contributed to the overall high levels of positive experience on group dynamics characteristics in both cohort and noncohort students. The professors in this particular leadership preparation program made deliberate attempts to involve students in cooperative learning activities, group discussions, and other shared activities during class sessions which in turn enhance positive perceptions of all students on participation, communication, collaboration, influence, and empowerment. However, the findings of significant differences between cohort students' ratings of trust, cohesiveness, and satisfaction could also be attributed to the fact that once in a cohort the students develop a sense of stability and familiarity with each other that makes the students feel a sense of belonging and overall fulfillment while progressing through a graduate leadership preparation program. Most people have adverse feelings to any changes that occur either at work or 


\section{Greenlee \& Karanxha / COHORT GROUP DYNAMICS}

family life. When students enroll in a cohort, they know from the beginning the sequence of the courses they will take, which semester that will occur, and they are familiar with all the students who would enroll in the same courses. So after a few courses they are aware of each other's idiosyncrasies, and learn what to expect from each other. In other words there are no surprises; there are no changes with the exception of the faculty members that teach different courses. To an extent, this could explain the high levels of trust, cohesiveness, and overall satisfaction of being in a cohort experience.

The findings have implications for educational leadership faculty that do not have cohorts in place as well. Clearly, being in a cohort has its benefits in some of group dynamics characteristics; however, programs that do not use cohorts can still achieve high levels of such characteristics without the structure of a cohort. Leadership programs need to establish high quality programs that are well organized, well run, and have high quality faculty. Also, faculty need to conscientiously engage in building learning communities who use group work and team building exercises that may positively influence group dynamics characteristics.

Cohorts have become established features of educational leadership preparation in many institutions across the country; however, our review of the literature suggests that the majority of the studies have examined only the cohort structure students without comparing them to non-cohort students and is descriptive in nature. Such a focus has mostly looked at the positive side of cohorts. Our study is the first one that has made an attempt to compare group dynamics of students in cohorts and non-cohorts and we encourage researchers to closely scrutinize the cohort structure and the types of effects it has on students. We suggest that a pre- and post study be conducted to conclude whether the structure of a cohort results in further development of cohesiveness and trust among students. Also, past studies (Barnett el al., 2000; Hill, 1995; Scribner \& Donaldson, 2001) have pointed to a sense of community and development of professional networking after students have completed their studies. However, we suggest that additional longitudinal studies be conducted in order to focus on this aspect of the use of cohorts to determine if indeed this is the case. Future studies could look at retention rates of students in cohorts compared to non-cohorts. Another study of interest would be one that looked at student performance on state assessments in both groups. The difference between the two groups of participants in our study regarding characteristics such as participation and communication was statistically insignificant, and our findings of effect size suggest that the effect sizes found do not carry practical significance either. Other studies that would closely scrutinize groupthink and creation of cliques in cohorts would shed more light on cohort experiences. Finally, advancement into leadership careers by both groups warrants the attention of researchers in the field. 


\section{References}

Alexander, M. (1985). The team effectiveness critique. In Goodstein, L. D. \& Pfeiffer, J. W. (Eds.), The 1985 Annual: Developing Human Resources (pp. 101-106). San Diego, CA: University Associates.

American Psychological Association (2001). Publication Manual of the American Psychological Association (5th ed.). Washington, DC: American Psychological Association.

Anderson, C. M., \& Martin, M. M. (1995). Why employees speak to coworkers and bosses: Motives, gender, and organizational satisfaction. Journal of Business Communication, 32(3), 249-265.

Bandura, A. (1997). Self-efficacy: The exercise of control. New York: Freeman.

Barnett, B. G., Basom, M. R., Yerkes, D. M., \& Norris, C. J. (2000). Cohorts in educational leadership preparation programs: Benefits, difficulties, and the potential for developing school leaders. Educational Administration Quarterly, 36(2), 255-282.

Barnett, B. G., \& Muse, I. D. (1993). Cohort groups in educational administration: Promises and challenges. Journal of School Leadership, 3, 400-415.
Basom, M., Yerkes, D., Norris, C., \& Barnett, B. (1996). Using cohorts as a means for developing transformational leaders. Journal of School Leadership, 6(1), 99-112.

Bass, B. M., \& Avolio, B. J. (Eds.). (1994). Improving organizational effectiveness through transformational leadership. Thousand Oaks, CA: Sage.

Browne-Ferrigno, T., \& Muth, R. (2001, November). Issues related to the effects of cohorts on learners. Paper presented at the Annual Meeting of the University Council for Educational Administration, Cincinnati, $\mathrm{OH}$.

Burnaford, G., \& Hobson, D. (1995). Beginning with the group: Collaboration as the cornerstone of graduate teacher education. Action in Teacher Education, 17(3), 67-75.

Burns, F., \& Gragg, R. L. (1981). Brief diagnostic instruments. The 1981 Annual handbook for group facilitators, San Diego: University Associates, pp. 87-94.

Carron, A. V. (1982). Cohesiveness in sport groups: Interpretations and considerations. Journal of Sport Psychology, 4, 123-138.

Cohen, J. (1988). Statistical power analysis for the behavioral sciences (2nd ed.). Hillsdale, NJ: Lawrence Erlbaum Associates. 
Cohen, S. G., \& Bailey, D. E. (1997). What makes teams work: Group effectiveness research from the shop floor to the executive suite. Journal of Management, 23, 239290.

Creswell, J. W. (2008). Educational research: Planning, conducting, and evaluating quantitative and qualitative research (3rd ed.). Upper Saddle, NJ: Merrill Prentice Hall.

Deutsch, M. (1973). The resolution of conflict. New Haven, CT: Yale University Press.

Donaldson, J. F., \& Scribner, J. P. (2003). Instructional cohorts and learning: Ironic uses of a social system. Journal of School Leadership, 11, 644-655.

Drury, J., \& Reicher, S. (1999). The intergroup dynamics of collective empowerment: Substantiating the social identity model of crowd behaviour. Group Processes and Intergroup Relations, 2, 1-22.

Durden, P. C. (2006). Creating connectivity: An urban collaboratory for preparation and practice in educational leadership. In Dembowski, F. L. \& Lemasters, L. (Eds.), Unbridled Spirit: Best Practices in Educational Administration--The 2006 Yearbook of the National Council of Professors of Educational Administration (NCPEA). Lancaster, PA: ProActive Publications.
Evans, C. R., \& Dion, K. L. (1991). Group cohesion and group performance: a meta-analysis.

Small Group Research, 22(2), 175186.

Festinger, L., Schachter, S., \& Back, K. (1950). Social pressures in informal groups: A study of human factors in housing. New York: Harper.

Fisher, B. A., \& Ellis, D. G. (1990). Small group decision making: Communication and the group process (3rd ed.). New York: McGraw Hill.

Forsyth, D. (1999). Group dynamics (3rd ed.). Belmont, CA: Brooks/ColeWadsworth.

Gross, N., \& Martin, W. E. (1952). On group cohesiveness. American Journal of Sociology, 57, 546-554.

Hecht, M. (1978). Measures of communication satisfaction. Human Communication Research, 4, 350-368.

Hedges, L. V., \& Olkin, I. (1985). Statistical methods for metaanalysis. New York: Academic Press.

Hill, M. S. (1995). Educational leadership cohort models: Changing the talk to change the walk. Planning and Changing, 26(3/4), 179-189.

Hill, M. S., \& Ragland, J. (1995). Women as educational leaders: Opening 


\section{Greenlee \& Karanxha / COHORT GROUP DYNAMICS}

windows, pushing ceilings. Thousand Oaks, CA: Corwin Press, Inc.

Hirokawa, R. Y. (1988). Group communication and decisionmaking performance: A continued test of the functional perspective. Human Communication Research, 14, 487515.

Hogarty, K. Y., \& Kromrey, J. D. (2001, April). We've been reporting some effect sizes: Can we guess what they mean? Paper presented at the annual meeting of the American Educational Research Association, Seattle, WA.

Hogg, M. A. (1993). Group cohesiveness: A critical review and some new directions. European Review of Social Psychology, 4, 85-111.

Jackson, B. L., \& Kelley, C. (2002). Exceptional and innovative programs in educational leadership. Educational Administration Quarterly, 38(2), 192-212.

Janis, I. L. (1982). Groupthink: Psychological studies of policy decisions and fiascoes (2nd ed.). Boston: Houghton Mifflin.

Janis, I. L., \& Mann, L. (1977). Decision making: A psychological analysis of conflict, choice, and commitment. New York: Free Press.
Johnson, D. W., \& Johnson, F. P. (2003). Joining together: Group theory and group skills ( $8^{\text {th }}$ ed.). Boston: Allyn \& Bacon.

Kirmeyer, S. L., \& Lin, T. (1987). Social support: Its relationship to observed communication with peers and superiors. Academy of Management Journal, 30, 138-151.

Larson, C. E., \& LaFasto. F. M. J. (1989). Team Work, What Must Go Right: What Can Go Wrong. Newbury Park, NJ: Sage.

Leithwood, K., Jantzi, D., \& Coffin, G. (1995). Preparing school leaders: What works. Toronto, Canada: Ontario Institute for Studies in Education.

Levine, A. (2005). Educating school leaders. Washington, DC: The Education Schools Project.

Maher, M. A. (2005). The evolving meaning and influence of cohort membership. Innovative Higher Education, 30(3), 195-211.

Malnight, T. (1989). GE-Preparing for the 1990's. Boston: HBS.

Mathieu, J. E., Gilson, L. L., \& Ruddy, T. M. (2006). Empowerment and team effectiveness: An empirical test of an integrated model. Journal of Applied Psychology, 91, 97-108.

McClure, B. A. (2005). Putting a new spin on groups: The science of chaos (2nd 


\section{Greenlee \& Karanxha / COHORT GROUP DYNAMICS}

ed.). Mahwah, NJ: Lawrence Erlbaum Associates.

McGrath, J. E. (1984) Groups: Interaction and performance. Englewood Cliffs, NJ: Prentice Hall, Inc.

Merriam, S. B., \& Caffarella, R. S. (1999). Learning in adulthood (2nd ed.). San Francisco: Jossey-Bass.

Mullen, B., \& Copper, C. (1994). The relation between group cohesiveness and performance: An integration. Journal of Applied Psychology, 115, 210-227.

Murphy, J. (1993). Alternative designs: New directions. In J. Murphy (Ed.), Preparing tomorrow's school leaders: Alternative designs (pp. 225-253). University Park, PA: University Council for Educational Administration.

National Commission on Excellence in Educational Administration (1987) Leaders for America's Schools. Tempe, AZ: University Council for Educational Administration.

Norris, C., \& Barnett, B. (1994, October). Cultivating a new leadership paradigm: From cohorts to communities. Paper presented at the annual meeting of the University Council for Educational Administration, Philadelphia, PA.

Norton, M. (1995). The status of student cohorts in educational administration preparation programmes. Tempe: Arizona State University, Division of Educational Leadership and Policy Studies.

Owen, W. F. (1985). Metaphor analysis of cohesiveness in small discussion groups. Small Group Behavior, 16 (3), 415-424.

Porter, A. C. (1987). Teacher collaboration: new partnerships to attack old problems. Phi Delta Kappan, 69 (2), 147-152.

Rosenfeld, L. B., \& Gilbert, J. R. (1989). The measurement of cohesion and its relationship to dimensions of self-disclosure in classroom settings. Small Group Research, 20(3), 291-301.

Rosenthal, R. (2000). Effect sizes in behavioral and biomedical research: Estimation and interpretation. In L. Bickman (Ed.), Validity $\mathcal{E}$ social experimentation (pp. 121- 139). London: Sage Publications, Inc.

Sapon-Shevin, M., \& Chandler-Olcott, K. (2001). Student cohorts: Communities of critique or dysfunctional families? Journal of Teacher Education, 52 (5), 350-64.

Schulz, A. J., Israel, B. A., \& Lantz, P. M. (2003). Instrument for Evaluating Dimensions of Group Dynamics Within Community-Based Participatory Research 
Partnerships. Evaluation and Program Planning, 26(3), 249-262.

Scribner, J. P., \& Donaldson, J. F. (2001). The dynamics of group learning in a cohort: From nonlearning to transformative learning. Educational Administration Quarterly, 37, 605-636.

Seashore, S. E., Lawler, E. E., III, Mirvis, P. H., \& Cammann, C. (1983). Assessing organizational change: A guide to methods, measures and practices. New York: Wiley.

Senge, P., Kleiner, A., Roberts, C., Ross, R. B., \& Smith, B. J. (1994). The fifth discipline fieldbook: Strategies and tools for building a learning organization. New York: Doubleday.

Shaw, M. E. (1981). Group dynamics: The psychology of small group behavior (3rd ed.). New York: McGrawHill.

Shea, G. P., \& Guzzo, R. A. (1987). Groups as human resources. In K. M. Rowland \& G. R. Ferris (Eds.), Research in personnel and human resource management (Vol. 5, pp. 323-356). Greenwich, CT: JAI Press.

Stokes, J. P. (1983). Components of group cohesion: Intermember attraction, instrumental value, and risk taking. Small Group Behavior, 14, 163-173.
Tareilo, J. (2007, June 18). The road to successfully completing the doctoral studies: A tale of a cohort model. Retrieved date, from http://cnx.org/content/m14600 /1.1/

Teitel, L. (1997). Understanding and harnessing the power of the cohort model in preparing educational leaders. Peabody Journal of Education, 72(2), 66-85.

Thanos, H. (1990). School-based teacher education. Australian Journal of Teacher Education, 15(1), 4-38.

Terry, D. J., \& Hogg, M. A. (1996). Group norms and the attitudebehavior relationship: A role for group identification. Personality and Social Psychology Bulletin, 22, 776-244.

Toseland, R. W., \& Rivas, R. F. (2001). An introduction to group work practice ( $4^{\text {th }}$ ed.). Boston: Allyn \& Bacon.

Turner, J. C., Hogg, M. A., Turner, P. J., \& Smith, P. M. (1984). Failure and defeat as determinants of group cohesiveness. British Journal of Social Psychology, 23, 97-111.

Vaske, J. J., Gliner, J. A., \& Morgan, G. A. (2002). Communicating judgments about practical significance: Effect size, confidence intervals and odds ratios. Human dimensions of Wildlife, 7, 287-300. 


\section{Greenlee \& Karanxha / COHORT GROUP DYNAMICS}

Whitaker, K. S., King, R., \& Vogel, L. R. (2004). School district-university partnerships: Graduate student perceptions of the strengths and weaknesses of reformed leadership development program. Planning and Changing, 35(3\&4), 209-222.

Young, M., \& Brewer, C. (2008). Fear and the preparation of school leaders: The role of ambiguity, anxiety, and power in meaning making. Educational Policy, 22(1), 106-129.
Zaccaro, S. J., \& McCoy, M. C. (1988). The effects of task and interpersonal cohesiveness on performance of a disjunctive group task. Journal of Applied Social Psychology, 18, 837-851.

Zand, D. (1972). Trust and managerial problem solving. Administrative Science Quarterly, 17, 229-239.

Zander, A. (1982). Making groups effective. San Francisco: JosseyBass. 
Greenlee \& Karanxha / COHORT GROUP DYNAMICS

\section{Appendices}


Greenlee \& Karanxha / COHORT GROUP DYNAMICS

\section{Appendix A}

Table 2

Descriptive statistics, standard t-test and effect size for group dynamics characteristics

DESCRIPTIVE

\begin{tabular}{|c|c|c|c|c|c|c|c|c|c|c|}
\hline $\begin{array}{l}\text { Group Dynamics } \\
\text { Characteristics }\end{array}$ & Cohort group & $\begin{array}{l}\text { Non-Cohort } \\
\text { group }\end{array}$ & 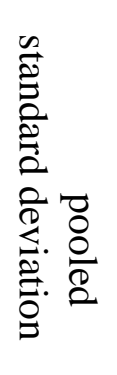 & 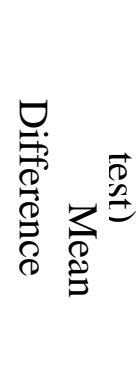 & 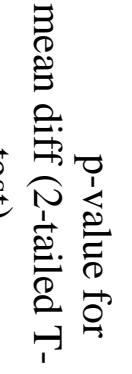 & $\begin{array}{l}\text { Confidence } \\
\text { Interval for } \\
\text { Difference }\end{array}$ & $\begin{array}{l}\text { Th } \\
\stackrel{7}{D} \\
\stackrel{2}{0} \\
\text { N. } \\
\text { D. }\end{array}$ & 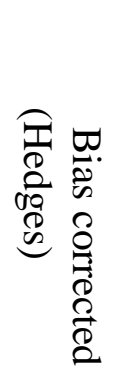 & 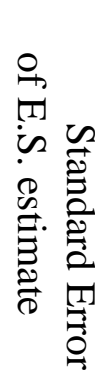 & $\begin{array}{l}\text { Confidence } \\
\text { Interval for } \\
\text { Effect Size }\end{array}$ \\
\hline
\end{tabular}

\begin{tabular}{|c|c|c|c|c|c|c|c|c|c|c|c|c|c|c|c|c|}
\hline & ean & & $\mathrm{D}$ & ean & & $\mathrm{D}$ & & & & ower & pper & & & & ower & pper \\
\hline Participation & .76 & 2 & .84 & .85 & 1 & .87 & .85 & 0.08 & .47 & 0.44 & .27 & 0.10 & 0.10 & .21 & 0.51 & .31 \\
\hline Communication & .16 & 2 & .70 & .12 & 1 & .73 & .72 & .04 & .78 & 0.26 & .34 & .06 & .06 & .21 & 0.35 & .47 \\
\hline Collaboration & .10 & 2 & .65 & .88 & 1 & .90 & .79 & .23 & .17 & 0.10 & .56 & .29 & .28 & .21 & 0.13 & .69 \\
\hline $\begin{array}{l}\text { Influence (reverse } \\
\text { scored) }\end{array}$ & .62 & 2 & .97 & .54 & 1 & .88 & .92 & .08 & .66 & 0.30 & .46 & .09 & .09 & .21 & 0.32 & .50 \\
\hline Trust & .37 & 2 & .56 & .88 & 1 & .77 & .69 & .49 & .00 & .20 & .77 & .71 & .71 & .21 & .28 & .13 \\
\hline & .41 & 2 & .83 & .82 & 1 & .08 & .97 & .59 & .00 & .19 & .99 & .61 & .60 & .21 & .18 & .02 \\
\hline Empowerment & .52 & 2 & .90 & .26 & 1 & .93 & .92 & .27 & .17 & 0.11 & .64 & .29 & .29 & .21 & 0.12 & .70 \\
\hline Satisfaction & .78 & 2 & .57 & .98 & 1 & .62 & .26 & .80 & .00 & .28 & .32 & .43 & .42 & .23 & .96 & .87 \\
\hline
\end{tabular}


Greenlee \& Karanxha / COHORT GROUP DYNAMICS

\section{Appendix B}

Figure 1. Effect size estimate (corrected) with upper and lower confidence limits at a 95\% confidence interval.

DESCRIPTIVE

\begin{tabular}{|c|c|c|c|c|c|c|c|c|c|c|}
\hline $\begin{array}{l}\text { Group Dynamics } \\
\text { Characteristics }\end{array}$ & Cohort group & $\begin{array}{l}\text { Non-Cohort } \\
\text { group }\end{array}$ & 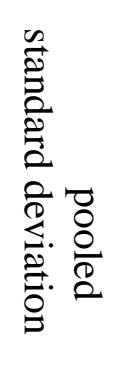 & 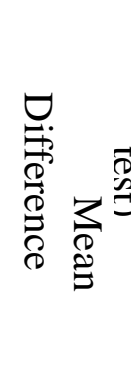 & 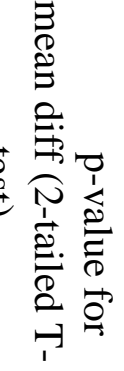 & $\begin{array}{l}\text { Confidence } \\
\text { Interval for } \\
\text { Difference }\end{array}$ & 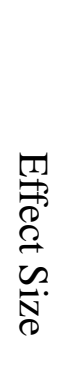 & 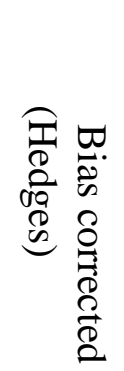 & 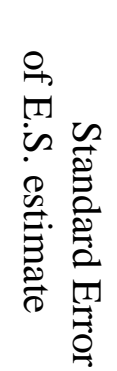 & $\begin{array}{l}\text { Confidence } \\
\text { Interval for } \\
\text { Effect Size }\end{array}$ \\
\hline
\end{tabular}

\begin{tabular}{|c|c|c|c|c|c|c|c|c|c|c|c|c|c|c|c|c|}
\hline & ean & & $\mathrm{D}$ & ean & & $\mathrm{D}$ & & & & ower & pper & & & & ower & pper \\
\hline Participation & .76 & 2 & .84 & .85 & 1 & .87 & .85 & 0.08 & .47 & 0.44 & .27 & 0.10 & 0.10 & .21 & 0.51 & .31 \\
\hline Communication & .16 & 2 & .70 & .12 & 1 & .73 & .72 & .04 & .78 & 0.26 & .34 & .06 & .06 & .21 & 0.35 & .47 \\
\hline Collaboration & .10 & 2 & .65 & .88 & 1 & .90 & .79 & .23 & .17 & 0.10 & .56 & .29 & .28 & .21 & 0.13 & .69 \\
\hline $\begin{array}{l}\text { Influence (reverse } \\
\text { scored) }\end{array}$ & .62 & 2 & .97 & .54 & 1 & .88 & .92 & .08 & .66 & 0.30 & .46 & .09 & .09 & .21 & 0.32 & .50 \\
\hline Trust & .37 & 2 & .56 & .88 & 1 & .77 & .69 & .49 & .00 & .20 & .77 & .71 & .71 & .21 & .28 & .13 \\
\hline Co & .41 & 2 & .83 & .82 & 1 & .08 & .97 & .59 & .00 & .19 & .99 & .61 & .60 & .21 & .18 & .02 \\
\hline Empowerment & .52 & 2 & .90 & .26 & 1 & .93 & .92 & .27 & .17 & 0.11 & .64 & .29 & .29 & .21 & 0.12 & .70 \\
\hline Satisfaction & .78 & 2 & .57 & .98 & 1 & .62 & .26 & .80 & .00 & .28 & .32 & .43 & .42 & .23 & .96 & .87 \\
\hline
\end{tabular}

